\title{
Comparison of the sensory properties of fragrant and non-fragrant rice (Oryza sativa), focusing on the role of the popcorn-like aroma compound 2-acetyl-1- pyrroline
}

Article

Accepted Version

Creative Commons: Attribution-Noncommercial-No Derivative Works 4.0

Wei, X., Sun, Q., Methven, L. and Elmore, S. (2020)

Comparison of the sensory properties of fragrant and nonfragrant rice (Oryza sativa), focusing on the role of the popcorn-like aroma compound 2-acetyl-1-pyrroline. Food Chemistry, 339. 128077. ISSN 0308-8146 doi:

https://doi.org/10.1016/j.foodchem.2020.128077 Available at https://centaur.reading.ac.uk/92780/

It is advisable to refer to the publisher's version if you intend to cite from the work. See Guidance on citing.

To link to this article DOI: http://dx.doi.org/10.1016/j.foodchem.2020.128077

Publisher: Elsevier

All outputs in CentAUR are protected by Intellectual Property Rights law, including copyright law. Copyright and IPR is retained by the creators or other copyright holders. Terms and conditions for use of this material are defined in the End User Agreement. 


\section{www.reading.ac.uk/centaur}

\section{CentAUR}

Central Archive at the University of Reading

Reading's research outputs online 
1 Comparison of the sensory properties of fragrant and non-fragrant rice

2 (Oryza sativa), focusing on the role of the popcorn-like aroma

3 compound 2-acetyl-1-pyrroline

4 Xuan Wei, Qianting Sun, Lisa Methven, J. Stephen Elmore*

5 Department of Food and Nutritional Sciences, University of Reading, Whiteknights, Reading

$6 \quad$ RG6 6AP, UK

7

8 Authors' information:

9 Xuan Wei: xuanwei40@outlook.com

10 Qianting Sun: sunqianting0118@gmail.com

11 Lisa Methven: 1.methven@reading.ac.uk

$12 *$ Corresponding author. Tel.: +44 118 3787455; fax: +44 1183787708 .

13 E-mail address: j.s.elmore@reading.ac.uk (J.S. Elmore). 


\section{Abstract}

2-Acetyl-1-pyrroline (2-AP) has been widely reported as a key contributor to the popcorn-like aroma of fragrant rice (Oryza sativa). To gain a greater understanding of its contribution to the aroma in both fragrant and non-fragrant rice, sensory profiling was conducted with a trained panel to examine the sensory properties of six boiled rice samples, three fragrant and three nonfragrant varieties. The intensity of the popcorn note as an orthonasal odour, a retronasal flavour and as an after-effect was significantly higher in fragrant rice than in non-fragrant rice. However, panellists could not differentiate these popcorn attributes between the three different fragrant rice varieties. 2-AP was extracted from the boiled rice samples by headspace solidphase microextraction and quantified by gas chromatography-mass spectrometry. 2-AP was below the limits of quantitation in non-fragrant varieties; however, gas chromatographyolfactometry of samples indicated the presence of 2-AP in both raw fragrant and non-fragrant rice varieties.

\section{Highlights:}

- 2-Acetyl-1-pyrroline (2-AP) is a key discriminator of fragrant and non-fragrant rice.

- Trained panel could not separate fragrant rice varieties with 2-fold variation in 2-AP.

- Popcorn-like aroma and flavour of 2-AP could be perceived in non-fragrant rice.

- The odour perception of 2-acetyl-1-pyrroline fits Stevens' law.

Keywords: 2-acetyl-1-pyrroline; sensory evaluation; fragrant rice; GC-MS; HS-SPME; GColfactometry 


\section{Introduction}

Rice (Oryza sativa) provides energy for $25 \%$ of the world's population (FAO, 2002) and in 2019-2020 contributed to $20.7 \%$ of worldwide total grain consumption (USDA, 2020). It can be categorised into two types depending on its aroma: fragrant rice and non-fragrant rice. According to the 2017 Rice Market Monitor report, non-fragrant long-grain and medium-grain rice constitute the majority of world trade $(79 \%)$. This report stated that the price of fragrant rice was more than double that of high quality non-fragrant rice (FAO, 2017).

The aroma of fragrant rice was first evaluated analytically in the early 1980s and was described as 'popcorn-like'. Perceived popcorn odour intensities in several fragrant rice varieties were ranked, and 2-acetyl-1-pyrroline was considered as the most important contributor to this odour (Buttery, Ling, Juliano, \& Turnbaugh, 1983). This volatile compound can contribute a popcorn-like aroma with a low detection threshold $(0.02 \mathrm{ng} / \mathrm{L}$ in air; Schieberle, 1991). It was first identified in boiled fragrant rice (Buttery, Ling, \& Juliano, 1982). This compound is not only present in fragrant rice, it can also be detected in many different raw food materials, such as hazelnuts, pandan leaf, and Manuka honey; in addition, 2-AP can also be detected in some manufactured food products, such as popcorn, wheat bread crusts, and on the surface of Mediterranean dried sausages, Parma ham and Italian-type salami, where it contributes key odour characteristics (Wei, Handoko, Pather, Methven \&, Elmore, 2017).

Sensory profiling, using techniques such as quantitative descriptive analysis (QDA), is used to describe and quantify product attributes. Lexicons of rice descriptors have been established in several studies, especially for fragrant rice (Goodwin et al., 1996; Piggott, Morrison, \& Clyne, 1991; Yau \& Liu, 1999). The selection of descriptors depends on the panellists' culture and their familiarity with the samples (Paule \& Powers, 1989). Several studies have indicated that the aroma contribution of 2-AP may be overemphasised in boiled 
fragrant rice. Yang, Shewfelt, Lee, and Kays (2008) reported that popcorn-like note might not be the only important attribute in boiled fragrant rice. In addition, Limpawattana, Yang, Kays, and Shewfelt (2008) reported that there was no correlation between popcorn flavour and 2-AP in boiled rice.

In this study, different boiled rice varieties were evaluated using quantitative descriptive analysis (QDA). A lexicon was developed for both boiled fragrant and non-fragrant rice varieties using a UK-based panel. This is the first time that a rice lexicon prepared by a UK-based sensory panel has been reported. Differences in flavour and odour between fragrant and non-fragrant rice were evaluated. In addition, 2-AP in boiled fragrant and non-fragrant rice varieties was quantified using headspace solid-phase microextraction (HS-SPME) and gas chromatography-mass spectrometry (GC-MS). The primary aim of this study was to determine the strength of the relationship between perceived popcorn-like flavour and 2-AP content in boiled fragrant and non-fragrant rice.

\section{Materials and Methods}

\subsection{Plant materials and chemicals}

Six varieties of milled (white) rice were obtained, including three fragrant rice varieties (basmati and Thai jasmine from ASDA supermarket (Reading, UK), Sintanur from Indonesian Centre for Rice Research) and three non-fragrant rice varieties (American long-grain from ASDA supermarket (Reading), Arirang from Korea Foods Company Limited (Reading), and Ciherang from Indonesian Centre for Rice Research). Only one batch of each rice variety was collected for both GC-MS and QDA analysis, in order to limit the variation between batches. Still mineral water (Harrogate Spring Water, Harrogate, UK) was used for sensory analysis and HPLC-grade water (Fisher, Loughborough, UK) was used for chemical analysis. 2-AP and 
partially deuterated 2-AP (2-AP- $\left.d_{2-5}\right)$ standards were used for 2-AP quantification (both 30,000 $\mathrm{mg} / \mathrm{kg}$ in dichloromethane (DCM); aromaLAB GmbH, Planegg, Germany).

\subsection{Quantitative descriptive analysis (QDA) in boiled rice}

All rice samples ( $200 \pm 1 \mathrm{~g}$ ) were weighed and then boiled using $300 \mathrm{~mL}$ mineral water in a rice cooker (0.8 L capacity; Lloytron PLC, Leigh, UK). To avoid cross contamination, especially 2-AP in fragrant rice contaminating non-fragrant rice, each rice variety was cooked in its own dedicated cooker. Rice samples were initially cooked with tap water. During vocabulary development, panellists provided 'tap water' or 'kettle-like' attributes from samples cooked in tap water. However, these attributes were absent in samples cooked in mineral water. Subsequently, Harrogate Spring mineral water was used for rice boiling. Cooking proceeded for $20 \mathrm{~min}$ before the rice cooker automatically turned to warm mode. The samples were kept warm $\left(>65^{\circ} \mathrm{C}\right)$ in the rice cooker for $20 \mathrm{~min}$ before serving to panellists for evaluation.

Sensory profiling using a quantitative descriptive analysis (QDA) approach was conducted for six rice samples, using 11 trained, UK-based panellists, 10 female and one male. The panellists had between 6 months and 10 years' experience of sensory analysis, were aged between 30 and 60, and all screened and monitored for their sensory acuity. Seven QDA sessions were conducted during the experiment: two sessions for vocabulary development, two for training and three for scoring the samples. One batch of each type of rice was prepared for each session.

A consensus vocabulary was developed for appearance, odour, taste, flavour, mouthfeel, and after-effects. After-effects included all attributes within the modalities of taste, flavour and mouthfeel that remained after samples were swallowed (ASTM International, 2009). Attribute definitions and references are given in Table 1. A pre-heated $\left(120^{\circ} \mathrm{C}\right.$ for $20 \mathrm{~min}$ in the oven) 
ceramic cup $(50 \mathrm{~mL})$ filled with boiled rice $(20 \mathrm{~g})$ covered by foil was served to panellists for developing odour attributes and another 20-g sample was then served in the same manner for developing all the other attributes. The scoring for each sample attribute was conducted in individual booths in duplicate on separate days; samples were labelled with three-digit codes and presented randomly in a balanced order. Data were collected using Compusense at-hand software (Compusense, Guelph, Canada) using unstructured line scales (0-100), except for the attribute "popcorn odour", where a structured scale was used with anchors at positions defined by the panel after sniffing various concentrations of the reference 2-AP.

References for 'porridge', 'rice pudding', 'milky' and 'starchy water' attributes were provided (Table 1). The panellists were trained in recognition and scaling of popcorn odour, using a series of dilutions of 2-AP standard. Five sniff strips (Sigma-Aldrich, St Louis, MO) were wetted with four concentrations of 2-AP in dichloromethane $(10,100,1000$ and 5000 $\mu \mathrm{g} / \mathrm{kg}$ ) and a blank dichloromethane solution. After all solvent was evaporated using a nitrogen stream, each strip was sealed in a 5-mL glass vial with screw lid. Each vial was only opened once and sniffed by one panellist. The blank and the standard with highest 2-AP concentration were first provided to each panellist for Nil and Extreme values on the 0-100 unstructured line scale. The panellists were then was asked to sniff and score the other three concentrations of 2-AP on the same line scale. The average score for each 2-AP reference was added onto all 0 100 line scales used to measure 'popcorn' odour in the rice sample scoring session. Five concentrations of 2-AP standard (blank included) were also provided to panellists before sample profiling (an individual set of standards was prepared for each panellist). Panellists were asked to sniff the 2-AP standards in a separate room prior to the profiling session.

\subsection{2-Acetyl-1-pyrroline quantification in boiled rice using solid-phase microextraction and} gas chromatography-mass spectrometry 

glass vials. Vials were sealed with metal screw caps possessing PTFE-faced silicone septa. The min and then cooled to room temperature. Finally, a $1.5-\mathrm{mL}$ aliquot of $2-\mathrm{AP}-d_{2-5}$ aqueous solution was added into the vials. The $2-\mathrm{AP}-d_{2-5}$ aqueous solution was prepared from 2-AP- $d_{2-}$ 5 in dichloromethane $(100 \mu \mathrm{g} / \mathrm{kg})$; dichloromethane was evaporated by $\mathrm{N}_{2}$ gas and replaced by an equal amount of HPLC-grade water. During the dichloromethane evaporation, a proportion of the 2-AP- $d_{2-5}$ could be lost due to the instability of this compound. Therefore, the 2-AP- $d_{2-}$ 5 aqueous solution was only prepared once in the whole experiment; it was used for all samples and calibration standards, in order to avoid variation during aqueous solution preparation.

Headspace solid-phase microextraction (HS-SPME) followed by gas chromatographymass spectrometry (GC-MS) has been widely used in the aroma compound analysis of rice, especially for 2-AP detection (Tulyathan, Srisupattarawanich, \& Suwanagul, 2008; Bryant \& McClung, 2011; Mathure Jawali, Thengane, \& Nadaf, 2014; Poonlaphdecha et al., 2016). Believing that a higher extraction temperature can improve release of volatile compounds from the food matrix, several studies have extracted 2-AP from rice using a high extraction temperature $\left(80{ }^{\circ} \mathrm{C}\right.$ to $\left.120{ }^{\circ} \mathrm{C}\right)$ (Grimm, Bergman, Delgado, \& Bryant, 2001; Bryant \& McClung, 2011; Mathure et al., 2014; Poonlaphdecha et al., 2016). However, Hopfer et al. (2016) suggested the use of a lower extraction temperature; they indicated that 2-AP may be generated at a high extraction temperature. Hence, to minimise 2-AP changes during extraction, the HS-SPME method used in this paper was modified from that of Hopfer et al. (2016). During method development, a series of extraction times (30 min, $45 \mathrm{~min}, 60 \mathrm{~min}$ and $75 \mathrm{~min}$ ) was examined, in order to select a time that provided the highest signal-to-noise ratio of 2-AP in the GC chromatogram; this occurred at $60 \mathrm{~min}$, with no further increase at $75 \mathrm{~min}$. Therefore, 60 min was subsequently used as the extraction time. 
Agilent, Santa Clara, CA), attached to a 6890 gas chromatograph with 5975 mass spectrometer with a 1-cm divinylbenzene/CarboxenTM/polydimethylsiloxane (DVB/CAR/PDMS) SPME fibre (Supelco, Bellefonte, PA) for $60 \mathrm{~min}$ at $40^{\circ} \mathrm{C}$ with agitation.

After extraction, the SPME fibre was desorbed in the GC injection port at $250{ }^{\circ} \mathrm{C}$ for $20 \mathrm{~min}$, in splitless mode, onto the front of a Zebron ZB-Wax column $(30 \mathrm{~m} \times 0.25 \mathrm{~mm} ; 1 \mu \mathrm{m}$ film thickness; Phenomenex, Torrance, CA). The carrier gas was helium at a constant column flow rate of $0.9 \mathrm{~mL} / \mathrm{min}$. The initial GC oven temperature was $40{ }^{\circ} \mathrm{C}$ held for $2 \mathrm{~min}$, then increased to $60{ }^{\circ} \mathrm{C}$ at the rate of $2{ }^{\circ} \mathrm{C} / \mathrm{min}$, at which point the rate was increased to $6{ }^{\circ} \mathrm{C} / \mathrm{min}$ and held for $35 \mathrm{~min}$ after the oven temperature reached $250{ }^{\circ} \mathrm{C}$. Electron ionisation (EI) was applied; ionisation energy was $70 \mathrm{eV}$, and the electron multiplier was set at $2824 \mathrm{~V}$. Full scan mode was used for analysis from $\mathrm{m} / \mathrm{z} 30$ to 280 . Selected ion monitoring was also applied (SIM/Scan mode); $\mathrm{m} / \mathrm{z}, 68, \mathrm{~m} / \mathrm{z}, 83$ and $\mathrm{m} / \mathrm{z} 111$ were monitored for 2-AP; $\mathrm{m} / \mathrm{z}, 86$ and $\mathrm{m} / \mathrm{z}, 114$ were monitored for 2-AP- $d_{2-5}$. Dwell time of monitored ions was set at $100 \mathrm{~ms} / \mathrm{ion}$. A blank sample was prepared from $1.5 \mathrm{~mL} 2-\mathrm{AP}-d_{2-5}$ aqueous solution $(100 \mu \mathrm{g} / \mathrm{kg})$ with no rice and no

2-AP standard present in a 20-mL SPME vial, and it was run by GC-MS before calibration standards and rice samples. Mass spectral fragments at $\mathrm{m} / \mathrm{z} 68, \mathrm{~m} / \mathrm{z} 83$ and $\mathrm{m} / \mathrm{z} 111$ were absent in $2-\mathrm{AP}-d_{2-5}$, which suggested that $2-\mathrm{AP}-d_{2-5}$ is an ideal internal standard for 2-AP quantification and $m / z, 86$ and $m / z, 114$ can be used to monitor 2-AP- $d_{2-5}$.

A matrix-matched calibration curve was established for accurate quantification of 2AP. Boiled American long-grain rice (non-fragrant rice) was used as the matrix for calibration curves. Although a response for 2-AP in chromatograms was detected in all six rice samples (trace levels of 2-AP were present in chromatograms of non-fragrant rice), American longgrain rice gave the lowest response for 2-AP among all of the rice samples studied. A prepared 
2-AP standard solution (5.5 mg/kg in dichloromethane) was used for this curve. American long-grain rice $(1 \mathrm{~g})$ with $1.5 \mathrm{~mL}$ HPLC grade water was boiled in a 20-mL glass SPME vial with lid in a $\mathrm{GC}$ oven at $100{ }^{\circ} \mathrm{C}$ for $20 \mathrm{~min}$ and then the vial was cooled to room temperature. Four calibration standards $(10 \mu \mathrm{g} / \mathrm{kg}, 50 \mu \mathrm{g} / \mathrm{kg}, 100 \mu \mathrm{g} / \mathrm{kg}$, and $200 \mu \mathrm{g} / \mathrm{kg})$ were prepared to create a calibration curve for 2-AP. For each calibration standard, $100 \mu \mathrm{L}$ 2-AP in DCM $(0.1$ $\mathrm{mg} / \mathrm{kg}, 0.5 \mathrm{mg} / \mathrm{kg}, 1 \mathrm{mg} / \mathrm{kg}, 2 \mathrm{mg} / \mathrm{kg}$ ) with $1.5 \mathrm{~mL} \mathrm{2-AP-} d_{2-5}$ aqueous solution (the same concentration as in the extracted rice samples) were then added into the boiled American longgrain rice matrix and analysed by HS-SPME and GC-MS. The calibration curve formula obtained from calibration standards was

$$
y=0.0118 x
$$

where, $y$ is (peak area of 2-AP)/(peak area of 2-AP- $d_{2-5}$ ) and $x$ is the concentration of 2-AP. The $r^{2}$ value of the calibration curve was 0.9856 ; recoveries of calibration standards containing $10 \mu \mathrm{g} / \mathrm{kg}, 50 \mu \mathrm{g} / \mathrm{kg}, 100 \mu \mathrm{g} / \mathrm{kg}$, and $200 \mu \mathrm{g} / \mathrm{kg}$ of $2-\mathrm{AP}$ were $175 \%, 108 \%, 76 \%$ and $104 \%$, respectively. Therefore, when measuring 2 -AP at a range between $50 \mu \mathrm{g} / \mathrm{kg}$ and 200 $\mu \mathrm{g} / \mathrm{kg}$, the calibration curve was acceptable.

2.4. Gas chromatography-olfactometry of raw fragrant and non-fragrant rice extracts prepared using solid-phase extraction

Raw, milled Sintanur or Ciherang rice flour $(10 \mathrm{~g} \pm 0.01 \mathrm{~g})$ was placed into a $50-\mathrm{mL}$ centrifuge tube and $35 \mathrm{~mL}$ HPLC-grade water were added. The tube was shaken for $20 \mathrm{~min}$ at 1700 rpm (Multi Reax; Heidolph, Schwabach, Germany), and then it was centrifuged at 7000 $\operatorname{rpm}(\approx 5100 \mathrm{~g})$ and $15{ }^{\circ} \mathrm{C}$ for $15 \mathrm{~min}$ (Sigma $3 \mathrm{~K} 10$ laboratory centrifuge; Sigma, Osterode, Germany). A 20-mL aliquot of the supernatant was collected for solid-phase extraction (SPE). The Isolute ENV+ cartridge (200 mg/6 mL; Biotage, Uppsala, Sweden) was firstly conditioned with $10 \mathrm{~mL}$ methanol, then with $10 \mathrm{~mL}$ HPLC-grade water. Then $20 \mathrm{~mL}$ rice supernatant were 
loaded onto the cartridge. After sample loading, the cartridge was washed with $10 \mathrm{~mL}$ HPLCgrade water. The washed cartridge was dried under vacuum for $30 \mathrm{~min}$. Finally, compounds were eluted with $2 \mathrm{~mL}$ DCM. The DCM extract was then concentrated with a nitrogen stream to around $100 \mu \mathrm{L}$. This concentrated extract was transferred to a $200-\mu \mathrm{L}$ glass insert (Thermo Scientific, Loughborough, UK) and then it was sealed in a 2-mL autosampler vial with metal crimp-cap prior to gas chromatography-olfactometry $(\mathrm{GC}-\mathrm{O})$ analysis.

A Zebron ZB-Wax column $(30 \mathrm{~m} \times 0.25 \mathrm{~mm}$; $0.25 \mu \mathrm{m}$ film thickness; Phenomenex, Torrance, CA) was used in this analysis. One microlitre of the extract was injected manually in split mode (split ratio of 20:1) into the injection port of a Hewlett Packard 5890 Series II gas chromatograph with olfactometer and flame ionisation detector (FID). The inlet temperature was $250{ }^{\circ} \mathrm{C}$ and the carrier gas was helium at 6.2 psi constant pressure. The initial GC oven temperature was $40{ }^{\circ} \mathrm{C}$ held for $2 \mathrm{~min}$, then increased to $200{ }^{\circ} \mathrm{C}$ at the rate of $4{ }^{\circ} \mathrm{C} / \mathrm{min}$, at which point the rate was increased to $15{ }^{\circ} \mathrm{C} / \mathrm{min}$ and held for $15 \mathrm{~min}$ after the oven temperature reached $250{ }^{\circ} \mathrm{C}$. The eluting compounds were split between the FID and sniff port with a split ratio of 1:1. Four trained sniffers were asked to sniff both Sintanur and Ciherang extracts in duplicate. A timer was started at the beginning of sample injection. The sniffers were asked to describe the odour they perceived, record the time point when they perceived the odour and rate the intensity of the odour from 0 (nil) to 10 (extreme). An alkane standard (C5-C22) was used to calculate linear retention index (LRI) values.

\subsection{Statistical analysis}

Sensory profiling data were collected by Compusense at-hand (version 8.8, Guelph, Canada) and analysed using Senpaq (v4.2, 2008; Qi Statistics, Reading, UK). Two-way ANOVA was used with sample fitted as a fixed effect and panellists as a random effect; effects were tested against the sample by panellist interaction. Significant differences between samples 
were assessed by Fisher's LSD pairwise comparison, and significance level was set at $p \leq 0.05$. To compare fragrant and non-fragrant rice samples as two groups, Student's $t$-test was carried out using XLSTAT software (2012, Addinsoft, Paris, France).

\section{Results and Discussion}

\subsection{Quantitative descriptive analysis (QDA) of boiled rice}

\subsubsection{2-Acetyl-1-pyrroline reference standard training}

Panellists from different cultures and with different experiences can have use different words to describe sensory attributes. Paule and Powers (1989) reported that descriptions of fragrant rice aroma by different groups were different. Orientals or frequent rice consumers described the predominant fragrant rice aroma as 'pandan-like'; however, non-Orientals or infrequent rice consumers described it as popcorn-like. The fragrant rice aroma in this study was initially described as 'popcorn-like', 'basmati-like' or 'jasmine rice-like' by 11 trained UK based panellists. 'Popcorn-like' is the major descriptor for this aroma. Buttery et al (1982) firstly described the aroma as 'popcorn-like' in fragrant rice and reported that it was contributed by 2-acetyl-1-pyrroline. The popcorn-like aroma in boiled rice was described as 'a dry, dusty, slightly toasted and slightly sweet aroma that can be specifically identified as popcorn' in the lexicon developed by Kansas State Expert Sensory Panel (Goodwin et al., 1996). Mahattanatawee and Rouseff (2014) described the fragrance in basmati, jasmine and Jasmati varieties as 'cooked jasmine rice-like' using $\mathrm{GC}-\mathrm{O}$ analysis. In the present study the description of this aroma was finally unified to 'popcorn-like' with the unanimous consent of all panellists. 2-AP standard was provided to panellists, to compare it with the fragrant odour in boiled rice samples. 
Panellists $(n=11)$ were asked to sniff five different concentrations of 2-AP standards

255

256

257

(blank (0), 10,100,1,000 and 5,000 $\mu \mathrm{g} / \mathrm{kg}$ ) and to score perceived intensity on an unstructured line scale (0-100) for popcorn aroma training, as described in Section 2.2. A ranking test for these five standards was conducted before training to ensure that all the panellists could differentiate and rank 2-AP standards without difficulty. This ranking test suggested that 5- to 10-fold differences in 2-AP standards could be detected by a trained UK panel. The blank standard was subsequently labelled as Nil and the $5,000 \mu \mathrm{g} / \mathrm{kg}$ standard was labelled as Extreme; these two standards were scored as 0 and 100 on the unstructured line scale. The other three standards $(10,100,1000 \mu \mathrm{g} / \mathrm{kg})$ were labelled as '1', '2', '3' from low to high concentration and panellists $(n=11)$ were asked to sniff and rate these three references using the line scale relative to the Nil and Extreme references. Results are shown in Figure 1a. Mean scores were then used as anchors at 12, 40 and 75 on the $0-100$ line scales for popcorn odour in the subsequent sample rating tests.

According to Stevens' law: “equal stimulus ratios result in equal sensation ratios rather than equal sensation differences" and his psychophysical power law was proposed as

$$
R=k S^{n}
$$

Therefore

$$
\log R=n \log S+\log k
$$

where $R$ is the response, $k$ is a constant, $S$ is the stimulus concentration, and $n$ is the modality-dependent exponent (Stone, Bleibaum, \& Thomas, 2012). The log-log plot between 2-AP concentration and perceived popcorn odour intensity follows Stevens' law and is shown in Figure 1b; exponent $n$ is 0.338 , denoting a decelerating relationship, as expected for aroma perception. This result indicates that with increasing 2-AP concentration, the perceived popcorn-like odour intensity increases but to a less than proportional extent. Therefore, it may 
be more difficult for panellists to notice changes of 2-AP concentration at higher concentrations than at lower concentrations.

\subsubsection{Boiled rice sensory attributes}

Thirty-seven attributes (covering appearance, mouthfeel, odour, taste, flavour, and after-effects) were quantified in the six boiled rice samples; however, significant differences between samples were only found in 8 attributes (Table 2). In physical modalities (appearance and mouthfeel), significant differences between samples were found for cohesive mouthfeel ( $p$ $<0.0001)$ and appearance attributes $(p<0.0001)$. The highest number of brown lines was observed in American long-grain and Ciherang rice, and the lowest number of brown lines was found in jasmine rice. Brown lines could not be observed on raw rice; they only appeared after rice boiling and they were only found on the surface of the rice grain. Brown lines were not present in every rice grain and this attribute was evaluated by how many grains with brown lines could be observed in one sample portion (50 g). The rice manufacturers suggested that the brown lines may be due to crack formation during rice postharvest processing or storage, where perhaps incomplete drying or long-term storage may cause more brown lines to develop. However, to our knowledge, this has not been reported in the literature.

After boiling, Arirang rice had the shortest rice grain and basmati rice had the longest rice grain, while basmati rice also gave the thinnest grains. The physical attributes in boiled rice, especially moisture content, stickiness and hardness are influenced by rice grain length and their starch content. Arirang rice had the highest 'wet' score and basmati had the lowest. Visible moisture differences may be caused by different water absorption abilities of the different rice varieties. Water absorption of rice grain is dependent on surface area, amylose and protein contents and gelatinisation temperature. Generally, long-grain varieties tend to absorb more water than short-grain varieties (Bett-Garber, Champagne, Ingram, \& McClung, 
2007). Therefore, as the same amount of water was added to all samples for boiling in this study, the shorter grain rice varieties (Arirang, Ciherang and Sintanur) appeared wetter than the three longer grain varieties.

The ratio of amylose to amylopectin in rice grain can significantly influence stickiness and hardness of boiled rice. Long-grain rice types (indica) usually contain more amylose and less amylopectin and can be harder and less sticky. In contrast, short-grain rice types (japonica) contain more amylopectin and less amylose; they are softer and stickier (Bao \& Bergman, 2004). The stickiness of boiled rice is caused by leached amylose and amylopectin interacting with each other, gelatinising and forming a coating on the surface of the grains (Bett-Garber et al., 2007). The differences in starch composition in the different rice varieties were expressed in their sensory attributes; high stickiness was expressed as lower grain separation appearance and higher cohesive mouthfeel scores. Effort to chew reflected the hardness of boiled rice grain.

Table 2 showed that basmati had highest grain separation and lowest cohesive mouthfeel. Arirang rice had the highest score for cohesive mouthfeel. However, no significant difference was found in this attribute between the six boiled rice varieties.

Of the 18 odour, taste and flavour attributes used to describe the boiled rice samples, only popcorn odour differed significantly between the samples $(p=0.028)$. Only 2 samples differed significantly for popcorn odour: the fragrant jasmine was significantly and substantially higher in popcorn odour than the non-fragrant Ciherang (difference of 24 in odour intensity rating score, $p=0.002$ in multiple pairwise comparison post ANOVA; Tukey HSD). The difference in popcorn flavour in mouth was not significant $(p=0.13)$, although the trend was the same (jasmine highest and Ciherang lowest) with a mean difference of 12 in flavour intensity rating score. Where popcorn was rated as an after-effect (flavour post-swallowing), the trend $(p=0.057)$ was for the fragrant Sintanur and jasmine varieties to be rated higher than the Ciherang. 
When the six rice varieties were grouped into fragrant rice (jasmine, basmati and

Sintanur) and non-fragrant rice (American long-grain, Arirang and Ciherang), $t$-test results of all of the odour and flavour-related attributes showed significant differences between fragrant and non-fragrant rice types in popcorn odour $(p=0.016)$, popcorn flavour $(p=0.026)$ and popcorn after-effect $(p=0.019)$, as shown in Figure 2. However, no differences were observed in the other rice and cereal-related odour and flavour attributes. Yang et al. (2008) reported that the popcorn-like note may not be the only important characteristic in boiled rice and other key characteristics contributed by other volatile compounds could be found in boiled fragrant rice. The results of this study concur with Yang et al., in that there were other aroma and flavour attributes present in boiled rice. However, none of these additional odours or flavours (Figure 2) differentiated the fragrant and non-fragrant rice types.

As discussed earlier, the differences in popcorn attributes between all different rice varieties were not obvious (Table 2). The significant difference in perceived popcorn odour was driven by jasmine and Ciherang. However, panellists found it difficult to differentiate popcorn odour in the other four boiled rice samples (basmati, Sintanur, American long-grain and Arirang). Although jasmine and Sintanur tended to show higher perceived popcorn flavour and after-effect than other samples, any differences between rice varieties were not significant (Table 2). These results indicate that although the panellists could not differentiate individual boiled rice varieties based on popcorn odour, flavour, or after-effect; fragrant and non-fragrant rice samples could be distinguished as two separate groups based on all three of these modalities.

Where the difference in popcorn odour between varieties was significant and any differences between in-mouth popcorn flavour and popcorn as an aftertaste were not, this may have been due to the use of the four reference anchors (2-AP standards) for training the assessors. This may have helped panellists to improve their discrimination of different boiled 
rice samples based on popcorn odour. However, the 2-AP standard training would have less effect in improving the discrimination of popcorn retronasal flavour and after-effect because the standards can only be sniffed; no standard levels of popcorn retronasal flavour and aftereffect were provided to panellists. The lack of flavour and aftertaste standards may have resulted in higher variation between panellists in popcorn flavour and after-effect than in odour, and hence resulted in a reduced likelihood of discrimination.

Popcorn was used as a reference material for 'popcorn' attributes in previous studies (Limpawattana et al., 2008; Limpawattana \& Shewfelt, 2010); it could have been used in the training of 'popcorn' odour, flavour, and after-effect. However, other aromas present in popcorn, such as 'smoky', may influence the understanding of 'popcorn-like' for panellists. Schieberle (1991) suggested that not only 'popcorn-like', but also 'fatty', 'coffee-like' and 'spicy' play important roles in the aroma of popcorn. In addition, intensities of 'popcorn' attributes cannot be controlled and adjusted in popcorn product during training.

\subsection{Quantification of 2-acetyl-1-pyrroline in boiled rice}

A matrix-matched calibration curve was established for 2-AP quantification in this study. Rice itself should be the best matrix to build this curve, because the structure of food including the starch content will significantly affect volatile compounds release from food matrix. Increasing viscosity or gelatinisation of a food matrix can significantly decrease mass transfer and therefore influence flavour release (Silva, Castro, \& Delgadillo, 2002). It was reported that release of aroma compounds is influenced by the amylose fraction in a gelatinisation matrix; in contrast amylopectin is unlikely to form strong inclusion complexes with aroma compounds (Silva et al., 2002).

It was discussed in Section 3.3.2 that the starch composition was reflected in grain separation, cohesiveness, and effort to chew. In "grain separation" attribute, basmati rice has a 
significantly higher score than the other rice varieties; in "cohesiveness" attribute, Arirang rice has a significantly higher score than American long-grain and basmati, while basmati has a significantly lower score than jasmine, Sintanur and Arirang rice. In "effort to chew" attribute, significant differences were not found among rice varieties (Table 2). More grain separation and less cohesiveness are associated with harder texture, which is caused by a higher content of amylose and a lower content of amylopectin; the converse is also true. Therefore, based on textural properties, basmati should be the rice variety containing the most amylose and Arirang the rice variety containing the least amylose, with intermediate values for the other four rice varieties. Hence, the matrix for the calibration curve should be selected from jasmine, Sintanur, Ciherang or American long-grain rice. 2-AP response was detected in the selected ion chromatograms $(\mathrm{m} / \mathrm{z} 68, \mathrm{~m} / \mathrm{z} 83$, and $\mathrm{m} / \mathrm{z} 111)$ of all six boiled rice varieties, three non-fragrant rice gave trace responses (lower than limit of quantification), and boiled American long-grain rice gave the lowest response. Therefore, boiled American long-grain rice was arguably the best choice as a matrix material for 2-AP calibration in this study.

Concentrations of 2-AP in the six boiled rice samples are shown in Figure 3. Significant differences in 2-AP concentrations were found between the three boiled fragrant rice samples $(p=0.028)$; jasmine rice contained most 2-AP $(146 \mu \mathrm{g} / \mathrm{kg})$, while the lowest 2-AP concentration in a boiled fragrant rice was in Sintanur $(80 \mu \mathrm{g} / \mathrm{kg})$. As the most popular fragrant rice on the UK market, basmati contained $113 \mu \mathrm{g} / \mathrm{kg}$ of 2-AP, which would explain why it was ranked in the middle of the three boiled fragrant rice varieties in this study for perceived intensity of popcorn odour, even though the difference in intensities between the three was not significant. Although a significant difference was found between the three fragrant rice samples in 2-AP concentration, there was only a two-fold difference between jasmine and Sintanur rice. The concentrations of the 2-AP standards used for popcorn odour training varied by 5 or 10 folds. Popcorn odour intensity of blank (0), 10, 100, 1000 and $5000 \mu \mathrm{g} / \mathrm{kg} 2$-AP reference 
standards were ranked, and results showed that the trained panellists could differentiate and

402

403

404

405

406

407

408

409

410

411

412

413

414

415

416

417

418

419

420

421

422

423

424

rank these samples in order of intensity with no difficulty. There was no evidence to show that a two-fold difference in 2-AP was great enough to be noticed by panellists, which might explain why there was no significant difference in popcorn odour, flavour or after-effect between the three fragrant rice samples. In addition, according to a log-log plot of 2-AP concentration and perceived popcorn odour intensity (Figure 1b), a decelerating relationship between 2-AP odour perception and 2-AP concentration may cause relatively more difficulty for panellists in discriminating higher 2-AP concentration samples and less difficulty in discriminating lower 2-AP concentration samples.

Limpawattana et al. (2008) reported that although 2-AP was the only contributor to popcorn-like note in boiled rice, there was no correlation between 2-AP concentration and perceived intensity of popcorn flavour. Their data showed that popcorn flavour had negative correlations with guaiacol and $(E, E)$-2,4-decadienal, which contributed smoky and fatty notes, respectively. They also reported that guaiacol was present in the popcorn they used for popcorn odour training, which might have affected the understanding of popcorn flavour. Guaiacol was not identified in the SPME extracts of any of the boiled rice samples in our study.

Yang et al. (2008) analysed 25 different odour-active compounds in five boiled fragrant rice samples and one boiled non-fragrant rice sample. They found that popcorn-like odour could be detected in both fragrant and non-fragrant rice varieties, and 2-AP was the only compound to contribute to this odour. Another study also evaluated 25 aroma-active compounds in fragrant and non-fragrant long-grain and medium-grain Italian rice. Again, 2AP was the only compound contributing popcorn-like odour (Griglione et al., 2015).

Compounds other than 2-AP may contribute roasty or popcorn-like aroma in popcorn, such as 2-acetyltetrahydropyridine and 2-propionyl-1-pyrroline (Schieberle, 1991). 2-Acetyl- 
2-thiazoline was reported to contribute to popcorn-like odour in boiled American-grown jasmine-style long-grain rice (Mahattanatawee \& Rouseff, 2014). This compound has a similar aroma to 2-AP and is much more stable than 2-AP (Rey, Bel-Rhlid, \& Juillerat, 2002). 2Acetyltetrahydropyridine, 2-propionyl-1-pyrroline and 2-acetyl-2-thiazoline were not detected in SPME extracts of boiled rice samples in the present study.

2-AP was detected in some non-fragrant rice varieties in previous studies using different extraction and quantification techniques; concentrations of 2-AP in non-fragrant rice have been reported from $0.6 \mu \mathrm{g} / \mathrm{kg}$ to $24.7 \mu \mathrm{g} / \mathrm{kg}$ (Buttery et al., 1983; Buttery, Turnbaugh, \& Ling, 1988; Maraval et al., 2010). The lowest concentration of 2-AP standard that could be quantified by GC-MS in our study was $5 \mu \mathrm{g} / \mathrm{kg}$ (see calibration curve preparation in Section 3.2.3.). Trace levels of key 2-AP ions $(\mathrm{m} / \mathrm{z} 68, \mathrm{~m} / \mathrm{z} 83$ and $\mathrm{m} / \mathrm{z} 111)$ were detected in samples which contained less than $5 \mu \mathrm{g} / \mathrm{kg}$ 2-AP; these trace peaks could not be quantified. In our study, 2-AP levels in three non-fragrant rice varieties were lower than the limit of quantification (5 $\mu \mathrm{g} / \mathrm{kg}$ ), although peaks for the key ions of 2-AP could be observed (Figure 3).

\subsection{Detection of 2-acetyl-1-pyrroline in raw rice by GC-olfactometry}

The sensory evaluation results showed that popcorn-like aroma can be perceived in boiled non-fragrant rice, although the intensity in non-fragrant rice is significantly lower than in fragrant rice. The odour thresholds of 2-AP are $0.1 \mathrm{~nL} / \mathrm{L}$ in water (Buttery et al., 1983) and $0.02 \mathrm{ng} / \mathrm{L}$ in air (Schieberle, 1991), levels which are much lower than the limit of quantification (LOQ) of our method ( $5 \mu \mathrm{g} / \mathrm{kg})$. Therefore, to confirm the presence of 2-AP or other popcornlike aroma contributors in non-fragrant rice samples, GC-olfactometry is likely to be a technique with higher sensitivity than GC-MS.

The trial tests on raw and boiled fragrant and non-fragrant rice using SPME followed by $\mathrm{GC}-\mathrm{O}$ showed that popcorn note could not be perceived in raw or boiled non-fragrant rice 
but could be perceived in raw and boiled fragrant rice; the compound which contributed this

450

451

452

453

454

455

456

457

458

459

460

461

462

463

464

465

466

467

468

469

470

471

472

473 popcorn-like note was identified as 2-AP based on its retention time. The SPME process that was used for GC-O may not have been sensitive enough, since only $1 \mathrm{~g}$ of rice sample was extracted, and only compounds in the rice headspace could be adsorbed. Moreover, only half of the extract reached the GC-O sniffer port while the other half was split to the FID. In addition, manual SPME instead of automatic SPME sampler was used with GC-O in our laboratory, and this may also reduce the sensitivity of the analysis since agitation did not occur during extraction when using manual SPME.

Therefore, the use of solid-phase extraction (SPE) as an extraction technique was investigated. The aqueous extract from $10 \mathrm{~g}$ of rice sample could be loaded onto the SPE cartridge and the dichloromethane used to elute the 2-AP could be concentrated to around 100 $\mu \mathrm{L}$ for analysis. In work carried out in our laboratory, gelatinisation of starch meant that the supernatant from the centrifuged boiled rice/water solution could hardly pass through the SPE sorbent. As Yoshihashi (2002) reported that 2-AP cannot be formed during rice boiling, it was decided to extract uncooked rice. Therefore, raw milled Sintanur (fragrant) and Ciherang (nonfragrant) were extracted and analysed by $\mathrm{GC}-\mathrm{O}$, to discover if popcorn aroma could be detected in non-fragrant rice by $\mathrm{GC}-\mathrm{O}$.

The results from the GC-O analysis (four assessors analysing each rice extract in duplicate) showed that popcorn-like odour was only perceived over an LRI range between 1330 and 1347 in both raw Sintanur and Ciherang rice. The LRI value of 2-AP on the same stationary phase (Zebron ZB-Wax) when used in the GC-MS analysis was 1333. Therefore, it seems likely that 2-AP was the sole contributor to perceived popcorn-like odour in both raw fragrant and non-fragrant rice. Sniffers rated aroma intensity from 0 (nil) to 10 (extreme) when compounds eluted from the GC column. Average perceived 2-AP intensity in Sintanur was $7.00 \pm 0.50$ and in Ciherang was $3.88 \pm 0.93$; Student's $t$-test showed that 2-AP intensity in 
Sintanur was significantly higher than in Ciherang $(p=0.0001)$. In addition, all the sniffers scored popcorn intensity higher for Sintanur rice than Ciherang rice.

The concentration of 2-AP in boiled fragrant rice was at least 15 -fold higher than that in boiled non-fragrant rice (based on the LOQ of 2-AP obtained using SPME with GC-MS) in our study; however, its perceived odour intensity in raw fragrant rice by $\mathrm{GC}-\mathrm{O}$ was only two times higher than in raw non-fragrant rice. As discussed in Section 3.1, the odour perception of 2-AP fits Steven's law and shows a decelerating relationship with increasing concentration. Since the detection threshold of 2-AP is $0.02 \mathrm{ng} / \mathrm{L}$ in air (Schieberle, 1991), which is much lower than the LOQ of 2-AP, the difference in 2-AP perceived intensity between fragrant and non-fragrant rice is somewhat less than the difference in 2-AP concentration.

Although 2-AP in non-fragrant rice could not be quantified by GC-MS in our laboratory, GC-O provided clear evidence that a low concentration of 2-AP was present in raw Ciherang non-fragrant rice. Based on the sensory profiling of boiled non-fragrant rice, it can be concluded that 2-AP can also contribute popcorn-like odour to non-fragrant rice. fragrant rice (Bradbury, Fitzgerald, Henry, Jin, \& Waters, 2005, Fitzgerald, McCouch, \& Hall, 2009). Due to the loss of function of the enzyme BADH2 caused by mutated badh2, the metabolite GABald is dehydrated to 1-pyrroline in fragrant rice (rather than forming $\gamma$ aminobutyric acid (GABA) through BADH2 catalysis) and then acetylated to 2-AP (Bradbury,

Gillies, Brusheet, Waters, \& Henry, 2008). However, as a positive correlation was found between 2-AP and the amino acid metabolite 1-pyrroline-5-carboxylate (P5C) in fragrant rice, a BADH2-independent pathway was proposed by Huang et al. (2008). Ornithine, glutamic acid, and proline can form $\mathrm{P} 5 \mathrm{C}$ through amino acid metabolism; P5C could be degraded to 1pyrroline then acetylated to 2-AP, or P5C could react with methylglyoxal to generate 2-AP 
directly. In the study of Huang et al. (2008), 2-AP was not detected in non-fragrant rice samples using GC-FID, as this technique is not sensitive enough to detect 2-AP in non-fragrant rice. Hence a correlation between P5C and 2-AP in non-fragrant rice was not reported. However, the presence of P5C and methylglyoxal was noted, which could generate a small amount of 2AP during non-fragrant rice growth.

While generation of 2-AP during growth of non-fragrant rice may occur, its formation post-harvest appears unlikely. Several studies have reported 2-AP losses in fragrant rice when it is dried and stored under a variety of conditions (Wongpornchai, Dumri, Jongkaewwattana, \& Sirri, 2004; Widjaja, Craske \& Wootton, 1996a,b). 2-AP formation was reported at $100{ }^{\circ} \mathrm{C}$ in a proline + methylglyoxal model system in phosphate buffer (Hofmann \& Schieberle, 1998), suggesting that boiling may generate 2-AP in rice. However, as stated earlier, Yoshihashi (2002) measured 2-AP in fragrant rice after heating at $90{ }^{\circ} \mathrm{C}$ without water, and boiling with water for $8,10,12$, and $14 \mathrm{~min}$, and concluded that 2 -AP could not be generated during rice cooking.

Detection of 2-AP is a limitation of the current study; only traces of 2-AP were detected in non-fragrant rice by GC-MS. GC with quadrupole-time-of-flight mass spectrometry could provide higher sensitivity and resolution than single quadrupole MS. For example, a problem in analysis of 2-AP by GC-MS is the coelution of 2-AP with 6-methyl-5-hepten-2-one on a polar GC column, both compounds having a number of fragment ions in common. However, these fragment ions with the same unit mass have different molecular formulae and would be readily separated under high resolution conditions, leading to an increase in the signal-to-noise ratio for 2-AP (Wei et al., 2017). The use of chemical ionisation (CI) rather than electron ionisation mass spectrometry could also improve detection sensitivity, as the former is a softer ionisation technique, producing a strong $\mathrm{M}+1$ ion at $\mathrm{m} / \mathrm{z} 112$ (Maraval et al., 2010). 
523 flavour, and after-effect) are the most important discriminators between fragrant and non-

524 fragrant boiled rice. Sensory profiling showed that significant differences were observed in

525 popcorn odour, flavour, and after-effect when fragrant and non-fragrant rice samples were

526 compared as two groups. 2-AP quantification concluded that significant differences in 2-AP

527 concentration between the three fragrant rice types were too small to cause differences in their

528 perceived popcorn-like aroma. Trace levels of 2-AP were found in non-fragrant rice by GC-

529 MS, and its presence in non-fragrant rice was confirmed by $\mathrm{GC}-\mathrm{O}$, but levels were lower than

530 the limit of quantification by GC-MS. At least 15 times higher levels of 2-AP were found in

531 fragrant rice than non-fragrant rice (based on the LOQ of 2-AP by GC-MS).

Our study emphasised that 2-AP is the most important aroma contributor in fragrant rice and confirmed that 2-AP and its popcorn-like aroma is the discriminator for fragrant and non-fragrant rice. However, the popcorn-like aroma of 2-AP can also be perceived in nonfragrant rice, although below the level of detection of the GC-MS used in this work.

\section{Acknowledgement}


ASTM international. (2009). Standard terminology relating to sensory evaluations of materials and products. ASTM International, (E253-09a). West Conshohocken, PA.

Bao, J., \& Bergman, C. J. (2004). The functionality of rice starch. Starch in food: structure, function, and applications. Cambridge: Woodhead Publishing Ltd.

Bett-Garber, K. L., Champagne, E. T., Ingram, D. A., \& McClung, A. M. (2007). Influence of water-to-rice ratio on cooked rice flavor and texture. Cereal Chemistry Journal, 84(6), 614-619.

Bradbury, L., Fitzgerald, T. L., Henry, R. J., Jin, Q., \& Waters, D. (2005). The gene for fragrance in rice. Plant Biotechnology Journal, 3, 363-370.

Bradbury, L., Gillies, S. A., Brusheet, D. J., Waters, D., \& Henry, R. J. (2008). Inactivation of an aminoaldehyde dehydrogenase is responsible for fragrance in rice. Plant Molecular Biology, 68(4-5), 439-449.

Bryant, R. J., \& McClung, A. M. (2011). Volatile profiles of aromatic and non-aromatic rice cultivars using SPME/GC-MS. Food Chemistry, 124, 501-513.

Buttery, R. G., Ling, L. C., \& Juliano, B. O. (1982). 2-Acetyl-1-pyrroline: an important aroma component of cooked rice. Chemistry and Industry, 12, 958-959.

Buttery, R. G., Ling, L. C., Juliano, B. O., \& Turnbaugh, J. G. (1983). Cooked rice aroma and 2-acetyl-1-pyrroline. Journal of Agricultural and Food Chemistry, 31, 823-826.

Buttery, R. G., Turnbaugh, J. G., \& Ling, L. C. (1988). Contribution of volatiles to rice aroma. Journal of Agricultural and Food Chemistry, 36(5), 1006-1009.

FAO. (2002). Status of the World Rice Market in 2002. http://www.fao.org/docrep/006/Y4751E/y4751e03.htm (accessed 8th November 2016).

FAO. (2017). Rice market monitor July 2017. URL: http://www.fao.org/fileadmin/templates/est/COMM_MARKETS_MONITORING/Ric e/Images/RMM/RMM-Jul17.pdf. (accessed 16th October 2018) 
Fitzgerald, M. A., McCouch, S. R., \& Hall, R. D. (2009). Not just a grain of rice: the quest for quality. Trends in Plant Science, 14, 133-139.

Goodwin, J., Koop, L. A., Rister, M. E., Miller, R. K., Maca, J. V., Chambers, E., Hollingsworth, M., Bett, K., Webb, B. D., \& McClung, A. M. (1996). Developing a common language for the U. S. rice industry: linkages among breeders, producers, processors and consumers. TAMRC Consumer Product Market Research CP2-96. Texas A\&M: College Station.

Griglione, A., Liberto, E., Cordero, C., Bressanello, D., Cagliero, C, Rubiolo, P., Bicchi, C., \& Sgorbini, B. (2015). High-quality Italian rice cultivars: chemical indices of ageing and aroma quality. Food Chemistry, 172, 305-313.

Grimm, C. C., Bergman, C., Delgado, T, J., \& Bryant, R. (2001) Screening for 2-acetyl-1pyrroline in the headspace of rice using SPME/GC-MS. Journal of Agricultural and Food Chemistry, 49, 245-249.

Hofmann, T., \& Schieberle, P. (1998). 2-Oxopropanal, hydroxy-2-propanone, and 1-pyrroline: Important intermediates in the generation of the roast-smelling food flavor compounds 2-acetyl-1-pyrroline and 2-acetyltetrahydropyridine. Journal of Agricultural and Food Chemistry, 46(6), 2270-2277.

Hopfer, H., Jodari, F., Negre-Zakharov, F., Wylie, P. L., \& Ebeler, S. E. (2016). HS-SPMEGC-MS/MS method for the rapid and sensitive quantitation of 2-acetyl-1-pyrroline in single rice kernels. Journal of Agricultural and Food Chemistry, 64(20), 4114-4120.

Huang, T. C., Teng, C. S., Chang, J. L., Chuang, H. S., Ho, C. T., \& Wu, M. L. (2008). Biosynthetic mechanism of 2-acetyl-1-pyrroline and its relationship with 1-pyrroline5-carboxylic acid and methylglyoxal in aromatic rice (Oryza sativa L.) callus. Journal of Agricultural and Food Chemistry, 56(16), 7399-7404.

Limpawattana, M., \& Shewfelt, R. L. (2010). Flavor lexicon for sensory descriptive profiling of different rice types. Journal of Food Science, 75, 199-205.

Limpawattana, M., Yang, D. S., Kays, S. J., \& Shewfelt, R. L. (2008). Relating sensory descriptors to volatile components in flavor for specialty rice types. Journal of Food Science, 73(9), 456-461. 
Mahattanatawee, K., \& Rouseff, R. L. (2014). Comparison of aroma active and sulfur volatiles in three fragrant rice cultivars using GC-olfactometry and GC-PFPD. Food Chemistry, $154,1-6$.

Maraval, I., Sen, K., Agrebi, A., Menut, C., Morere, A., Boulanger, R., Gay, F., Mestres, C., \& Gunata, Z. (2010). Quantification of 2-acetyl-1-pyrroline in rice by stable isotope dilution assay through headspace solid-phase microextraction coupled to gas chromatography-tandem mass spectrometry. Analytica Chimica Acta, 675,148-155.

Mathure, S. V., Jawali, N., Thengane, R. J., \& Nadaf, A. B. (2014). Comparative quantitative analysis of headspace volatiles and their association with BADH2 marker in nonbasmati scented, basmati and non-scented rice (Oryza sativa L.) cultivars of India. Food Chemistry, 142, 383-391.

Paule, C. M., \& Powers, J. J. (1989). Sensory and chemical examination of aromatic and nonaromatic rice. Journal of Food Science, 54, 1515-1520.

Piggott, J. R., Morrison, W. R., \& Clyne, J. (1991). Changes in lipids and in sensory attributes on storage of rice milled to different degrees. International Journal of Food Science and Technology, 26, 615-628.

Poonlaphdecha, J., Gantet, P., Maraval, I., Sauvage, F. X., Menut, C., Morere, A., Boulanger, R., Wust, M., \& Gunata, Z. (2016). Biosynthesis of 2-acetyl-1-pyrroline in rice calli cultures: demonstration of 1-pyrroline as a limiting substrate. Food Chemistry, 197, 965-971.

Rey, Y. F., Bel-Rhlid, R., \& Juillerat, M. (2002). Biogeneration of 2-(1-hydroxyethyl)-4,5dihydrothiazole as precursor of roasted and popcorn-like aroma for bakery products. Journal of Molecular Catalysis B: Enzymatic, 19-20, 473-477.

Schieberle, P. (1991). Primary odorants in popcorn. Journal of Agricultural and Food Chemistry, 39(6), 1141-1144.

Silva, J. A., Castro, S., \& Delgadillo, I. (2002). Effect of gelatinization and starch-emulsifier interactions on aroma release from starch-rich model systems. Journal of Agricultural and Food Chemistry, 50, 1976-1984. 
Stone H., Bleibaum, R. N., \& Thomas, H. A. (2012). Sensory evaluation practices. (4 ed). London: Academic press.

Tulyathan, V., Srisupattarawanich, N., \& Suwanagul, A. (2008). Effect of rice flour coating on 2-acetyl-1-pyrroline and $n$-hexanal in brown rice cv. Jao Hom Supanburi during storage. Postharvest Biology and Technology, 47, 367-372.

USDA. (2020), Grain: world markets and trade. https://apps.fas.usda.gov/psdonline/circulars/grain.pdf (accessed 5th August 2020)

Wei, X., Handoko, D. D., Pather, L., Methven, L., \& Elmore, J. S. (2017). Evaluation of 2acetyl-1-pyrroline in foods, with an emphasis on rice flavour. Food Chemistry, 232, 531-544.

Widjaja, R., Craske, J., \& Wootton, M. (1996a). Comparative studies on volatile components of non-fragrant and fragrant rices. Journal of the Science of Food and Agriculture, 70, $151-161$.

Widjaja, R., Craske, J. D., \& Wootton, M. (1996b). Changes in volatile components of paddy, brown and white fragrant rice during storage. Journal of the Science of Food and Agriculture, 71, 218-224.

Wongpornchai, S., Dumri, K., Jongkaewwattana, S., \& Sirri, B. (2004). Effects of drying methods and storage time on the aroma and milling quality of rice (Oryza sativa L.) cv. Khao Dawk Mali 105. Food Chemistry, 87(3), 407-414.

Yang, D. S., Shewfelt, R. L., Lee, K. S., \& Kays, S. J. (2008). Comparison of odor-active compounds from six distinctly different rice flavor types. Journal of Agricultural and Food Chemistry, 56(8), 2780-2787.

Yau, N. J. N., \& Liu, T. T. (1999). Instrumental and sensory analysis of volatile aroma of cooked rice. Journal of Sensory Studies, 14(2), 209-233.

Yoshihashi, T. (2002). Quantitative analysis on 2-acetyl-1-pyrroline of an aromatic rice by stable isotope dilution method and model studies on its formation during cooking. Journal of Food Science, 67(2), 619-622. 
654 Figure 1: (a) Mean perceived intensity of odour of 2-acetyl-1-pyrroline (2-AP) standard

655

656

657

658

659

660

661

662

663

664

665

666

667 references $(0,10,100,1000$ and $5000 \mu \mathrm{g} / \mathrm{kg}$ ) assessed by 11 panellists; (b) log stimulus $v s$ log response plot of perceived intensities of odour of 2-AP standard references $(10,100,1000$ and $5000 \mu \mathrm{g} / \mathrm{kg})$ from 11 panellists. Error bars represent standard error of the mean.

Figure 2: Perceived intensities of odour, taste, and flavour-related attributes for fragrant and non-fragrant rice types. The numbers above the bars indicate the probability that the samples are significantly different $(p<0.05$; Student's $t$-test). Error bars represent standard error of the mean.

Figure 3: 2-AP concentrations in six boiled rice samples. Bars not sharing a common letter are significantly different $(p<0.05)$. Error bar represents standard deviations. 'trace': concentration lower than $5 \mu \mathrm{g} / \mathrm{kg}$. 

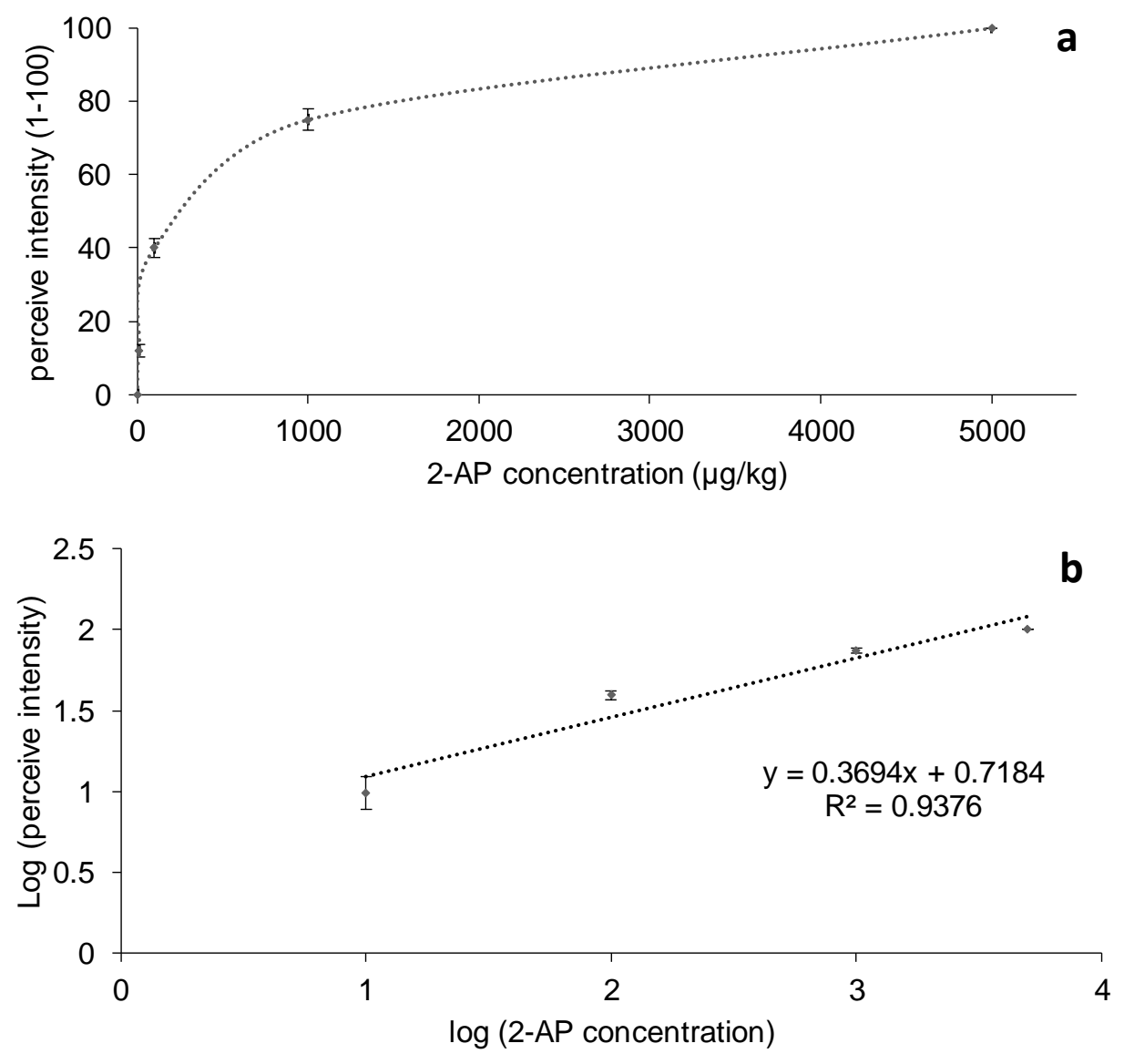

668

669

670 Figure 1: (a) Mean perceived intensity of odour of 2-acetyl-1-pyrroline (2-AP) standard references $671(0,10,100,1000$ and $5000 \mu \mathrm{g} / \mathrm{kg})$ assessed by 11 panellists; (b) $\log$ stimulus $v s$ log response plot of 672 perceived intensities of odour of 2-AP standard references $(10,100,1000$ and $5000 \mu \mathrm{g} / \mathrm{kg}$ ) from 11 673 panellists. Error bars represent standard error of the mean.

674

675

676 


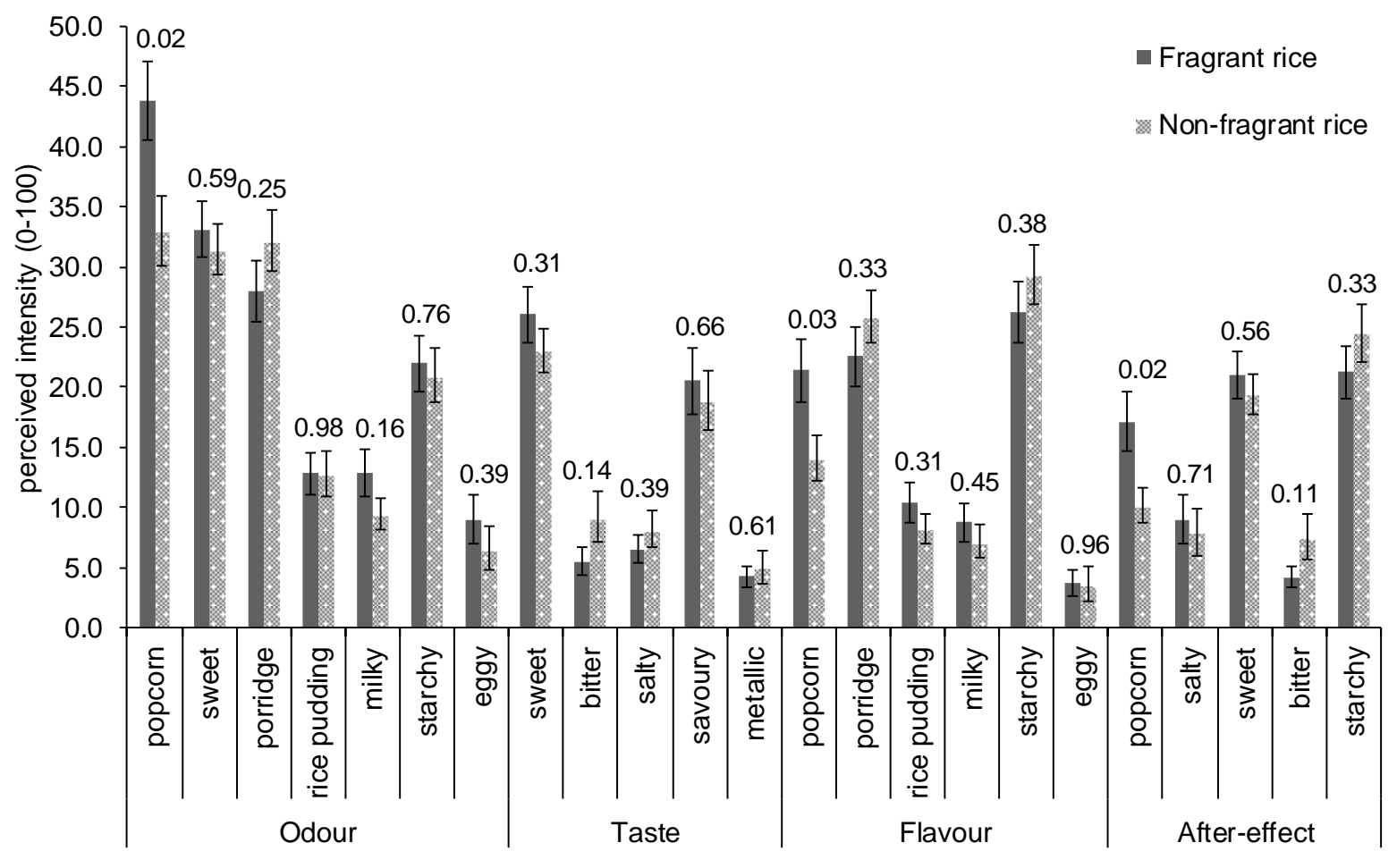

678

679 Figure 2: Perceived intensities of odour, taste and flavour-related attributes for fragrant and non-

680 fragrant rice types. The numbers above the bars indicate the probability that the samples are

681 significantly different ( $p<0.05$; Student's $t$-test). Error bars represent standard error of the mean.

682

683

684

685 


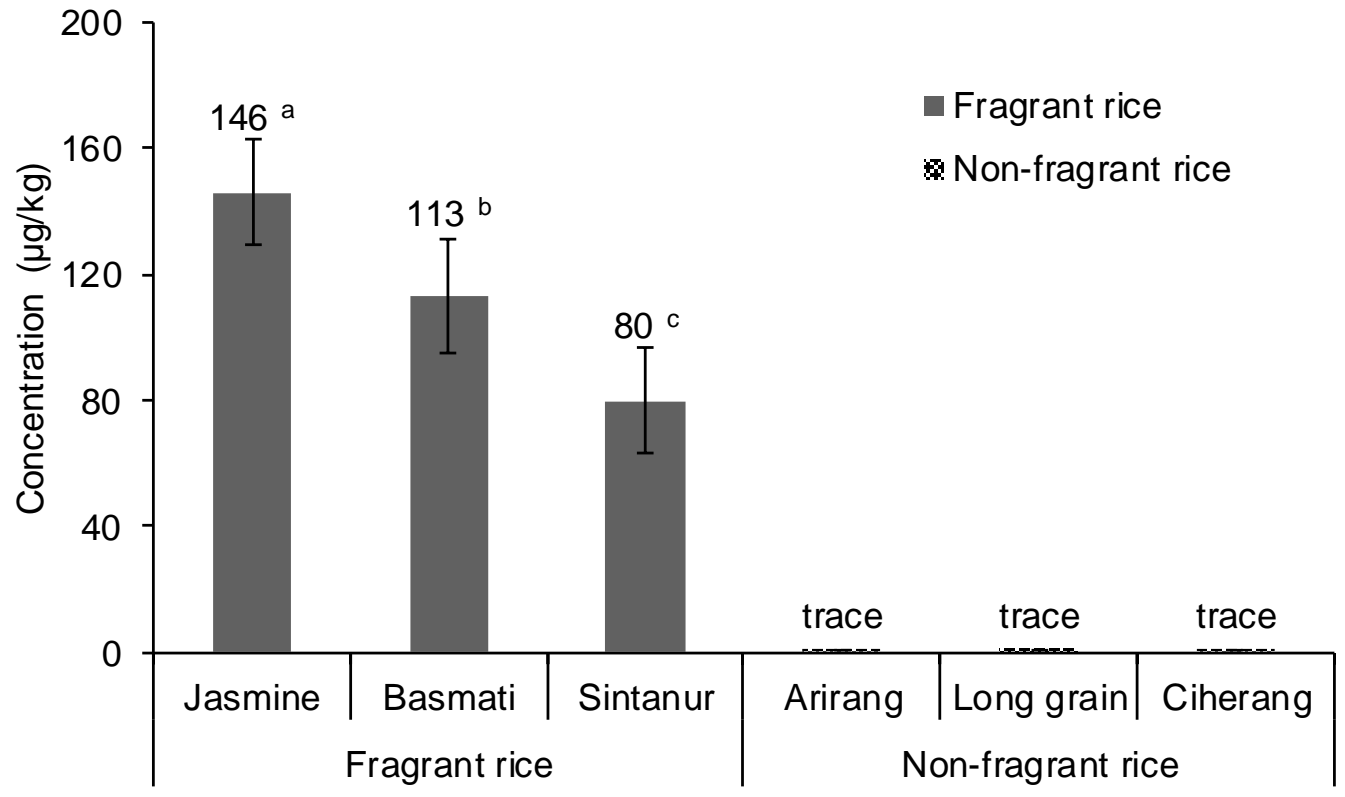

687

688 Figure 3: 2-AP concentrations in six boiled rice samples. Bars not sharing a common letter are

689 significantly different $(p<0.05)$. Error bar represents standard deviations. 'trace': concentration lower 690 than $5 \mu \mathrm{g} / \mathrm{kg}$.

691

692 
Table 1: Consensus vocabulary for boiled rice developed by 11 trained UK panellists during sensory 694 profiling.

\begin{tabular}{|c|c|c|c|}
\hline attributes & definition & reference & anchors \\
\hline \multicolumn{4}{|l|}{ appearance } \\
\hline brown lines & $\begin{array}{l}\text { extent of brown lines on } \\
\text { the surface of rice grains }\end{array}$ & & nil to extreme \\
\hline wet & moistness of rice grain & & dry to wet \\
\hline yellow & colour of rice grain & & white to yellow \\
\hline uniform & shape of rice grain & & $\begin{array}{l}\text { irregular to } \\
\text { regular }\end{array}$ \\
\hline $\begin{array}{l}\text { separated } \\
\text { grain }\end{array}$ & $\begin{array}{l}\text { separation between rice } \\
\text { grains after cooking }\end{array}$ & & $\begin{array}{l}\text { unseparated to } \\
\text { separated }\end{array}$ \\
\hline length & length of rice grain & & short to long \\
\hline thickness & thickness of rice grain & & thin to thick \\
\hline \multicolumn{4}{|l|}{ mouthfeel } \\
\hline smooth & $\begin{array}{l}\text { smoothness of the sample } \\
\text { on chewing }\end{array}$ & & nil to extreme \\
\hline effort to chew & $\begin{array}{l}\text { springiness of the sample } \\
\text { on chewing }\end{array}$ & & nil to extreme \\
\hline drying & mouth drying & & nil to extreme \\
\hline cohesive & stickiness of rice grain & & nil to extreme \\
\hline watery & $\begin{array}{l}\text { how moist the sample felt } \\
\text { in the mouth }\end{array}$ & & nil to extreme \\
\hline \multicolumn{4}{|l|}{ odour } \\
\hline popcorn & aroma of popcorn & $\begin{array}{l}\text { Five sniff stripes wetted in a } \\
\text { blank solution and four } \\
\text { levels of } 2 \text {-acetyl-1- } \\
\text { pyrroline standard }(10,100, \\
1000 \text { and } 5000 \mu \mathrm{g} / \mathrm{kg}) \text { and } \\
\text { placed in sniff bottles }\end{array}$ & $\begin{array}{l}\text { nil to extreme, } \\
\text { standards were } \\
\text { given as three } \\
\text { anchors at } 0,12 \text {, } \\
40,75 \text { and } 100 \\
\text { along the line } \\
\text { scale }\end{array}$ \\
\hline sweet & aroma of Demerara sugar & Demerara sugar & nil to extreme \\
\hline porridge & $\begin{array}{l}\text { aroma of cooked oat } \\
\text { porridge }\end{array}$ & $\begin{array}{l}\text { Quaker wholegrain rolled } \\
\text { oats porridge (Quaker, UK) }\end{array}$ & nil to extreme \\
\hline rice pudding & aroma of rice pudding & $\begin{array}{l}\text { Ambrosia original tinned } \\
\text { rice pudding (Ambrosia, } \\
\text { UK) }\end{array}$ & nil to extreme \\
\hline milky & aroma of uncooked milk & $\begin{array}{l}\text { pasteurised Tesco skim milk } \\
\text { (Tesco, UK) }\end{array}$ & nil to extreme \\
\hline starchy water & $\begin{array}{l}\text { aroma of starch water } \\
\text { from boiled non-fragrant } \\
\text { rice }\end{array}$ & $\begin{array}{l}\text { cold starchy water collected } \\
\text { from boiled non-fragrant } \\
\text { rice }\end{array}$ & nil to extreme \\
\hline eggy & aroma of boiled egg & & nil to extreme \\
\hline
\end{tabular}




\begin{tabular}{|c|c|c|c|}
\hline \multicolumn{4}{|l|}{ taste } \\
\hline sweet & elicited by sucrose & & nil to extreme \\
\hline bitter & elicited by caffeine & & nil to extreme \\
\hline salty & $\begin{array}{l}\text { elicited by sodium } \\
\text { chloride }\end{array}$ & & nil to extreme \\
\hline savoury & brothy or meaty & & nil to extreme \\
\hline metallic & metal-like & & nil to extreme \\
\hline \multicolumn{4}{|l|}{ flavour } \\
\hline popcorn & flavour of popcorn & & nil to extreme \\
\hline porridge & flavour of oat porridge & $\begin{array}{l}\text { Quaker wholegrain rolled } \\
\text { oats porridge (Quaker, UK) }\end{array}$ & nil to extreme \\
\hline rice pudding & flavour of rice pudding & $\begin{array}{l}\text { Ambrosia original tinned } \\
\text { rice pudding (Ambrosia, } \\
\text { UK) }\end{array}$ & nil to extreme \\
\hline milky & flavour of uncooked milk & $\begin{array}{l}\text { pasteurised Tesco skim milk } \\
\text { (Tesco, UK) }\end{array}$ & nil to extreme \\
\hline starchy water & $\begin{array}{l}\text { flavour of starch water } \\
\text { from boiled non-fragrant } \\
\text { rice }\end{array}$ & $\begin{array}{l}\text { cold starchy water collected } \\
\text { from boiled non-fragrant } \\
\text { rice }\end{array}$ & nil to extreme \\
\hline eggy & flavour of boiled egg & & nil to extreme \\
\hline \multicolumn{4}{|l|}{ after-effect } \\
\hline popcorn & $\begin{array}{l}\text { residual popcorn odour } \\
\text { and flavour in mouth after } \\
\text { swallowing }\end{array}$ & & nil to extreme \\
\hline salty & $\begin{array}{l}\text { residual saltiness in mouth } \\
\text { after swallowing }\end{array}$ & & nil to extreme \\
\hline sweet & $\begin{array}{l}\text { residual sweetness in } \\
\text { mouth after swallowing }\end{array}$ & & nil to extreme \\
\hline bitter & $\begin{array}{l}\text { residual bitterness in } \\
\text { mouth after swallowing }\end{array}$ & & nil to extreme \\
\hline drying & $\begin{array}{l}\text { mouth drying after } \\
\text { swallowing }\end{array}$ & & nil to extreme \\
\hline residue & $\begin{array}{l}\text { particulates left in mouth } \\
\text { after swallowing }\end{array}$ & & nil to extreme \\
\hline starchy water & $\begin{array}{l}\text { starchy water flavour in } \\
\text { mouth after swallowing }\end{array}$ & & nil to extreme \\
\hline
\end{tabular}


Table 2: Mean value and significance of sensory attributes for six boiled rice types. Where values in a

699 row do not share the same letter, they are significantly different $(p<0.05$, Fishers LSD)

\begin{tabular}{|c|c|c|c|c|c|c|c|}
\hline \multirow[b]{3}{*}{ attributes } & \multicolumn{6}{|c|}{ Mean value of perceived intensity $(0-100)$} & \multirow{3}{*}{$\begin{array}{l}\text { effect } \\
\text { of rice } \\
\text { type ( } p \text { - } \\
\text { value) }\end{array}$} \\
\hline & \multicolumn{3}{|c|}{ fragrant rice } & \multicolumn{3}{|c|}{ non-fragrant rice } & \\
\hline & Jasmine & Basmati & $\begin{array}{l}\text { Sintanu } \\
\mathbf{r}\end{array}$ & Arirang & $\begin{array}{l}\text { Americ } \\
\text { an long- } \\
\text { grain }\end{array}$ & $\begin{array}{l}\text { Ciheran } \\
\text { g }\end{array}$ & \\
\hline \multicolumn{8}{|l|}{ appearance } \\
\hline wet & $28.9^{\mathrm{ab}}$ & $5.86^{\mathrm{c}}$ & $30.3^{\mathrm{ab}}$ & $35.2^{\mathrm{a}}$ & $15.4^{\mathrm{bc}}$ & $28.9^{\mathrm{ab}}$ & $<0.0001$ \\
\hline yellow & 14.8 & 16.2 & 20.7 & 24.3 & 13.7 & 14.6 & 0.203 \\
\hline brown lines & $1.99^{\mathrm{c}}$ & $4.50^{\mathrm{abc}}$ & $2.93^{\mathrm{bc}}$ & $10.0^{\mathrm{ab}}$ & $10.6^{\mathrm{a}}$ & $11.4^{\mathrm{a}}$ & $<0.0001$ \\
\hline uniform & $64.4^{\mathrm{a}}$ & $71.4^{\mathrm{a}}$ & $57.5^{\mathrm{ab}}$ & $56.3^{\mathrm{ab}}$ & $41.9^{\mathrm{b}}$ & $55.5^{\mathrm{ab}}$ & $<0.0001$ \\
\hline $\begin{array}{l}\text { separated } \\
\text { grain }\end{array}$ & $47.8^{\mathrm{ab}}$ & $56.5^{\mathrm{a}}$ & $41.5^{\mathrm{ab}}$ & $31.5^{\mathrm{b}}$ & $31.4^{\mathrm{b}}$ & $36.9^{\mathrm{b}}$ & $<0.0001$ \\
\hline length & $56.6^{\mathrm{ab}}$ & $71.9^{\mathrm{a}}$ & $38.1^{\mathrm{c}}$ & $37.7^{\mathrm{c}}$ & $46.1^{\mathrm{bc}}$ & $49.1^{\mathrm{bc}}$ & $<0.0001$ \\
\hline $\begin{array}{l}\text { thickness } \\
\text { odour }\end{array}$ & $51.5^{\mathrm{a}}$ & $29.7^{b}$ & $55.7^{\mathrm{a}}$ & $65.4^{\mathrm{a}}$ & $51.9^{\mathrm{a}}$ & $53.0^{\mathrm{a}}$ & $<0.0001$ \\
\hline \multicolumn{7}{|l|}{ odour } & 0.028 \\
\hline sweet & 39.3 & 32.1 & 28.0 & 31.1 & 34.8 & 28.3 & 0.297 \\
\hline porridge & 31.8 & 26.6 & 25.5 & 35.6 & 30.2 & 30.7 & 0.647 \\
\hline rice pudding & 16.8 & 9.90 & 11.9 & 14.5 & 13.7 & 10.1 & 0.609 \\
\hline milky & 16.1 & 12.0 & 10.6 & 11.0 & 10.0 & 7.34 & 0.479 \\
\hline starchy water & 21.3 & 22.0 & 22.6 & 16.0 & 19.2 & 27.8 & 0.442 \\
\hline eggy & 9.32 & 10.1 & 7.42 & 2.72 & 6.30 & 10.8 & 0.572 \\
\hline \multicolumn{8}{|l|}{ taste } \\
\hline sweet & 27.5 & 23.8 & 27.0 & 24.9 & 23.2 & 21.0 & 0.819 \\
\hline bitter & 8.92 & 3.15 & 4.44 & 8.12 & 10.8 & 8.70 & 0.472 \\
\hline salty & 7.88 & 4.79 & 6.91 & 8.88 & 6.94 & 8.70 & 0.843 \\
\hline savoury & 19.0 & 23.3 & 19.3 & 22.3 & 15.6 & 18.7 & 0.875 \\
\hline metallic & 4.20 & 3.29 & 5.19 & 4.15 & 6.57 & 4.49 & 0.909 \\
\hline \multicolumn{8}{|l|}{ flavour } \\
\hline popcorn & 24.5 & 16.2 & 23.5 & 17.3 & 12.8 & 12.2 & 0.134 \\
\hline porridge & 22.7 & 22.8 & 22.2 & 30.8 & 24.0 & 22.8 & 0.691 \\
\hline rice pudding & 13.5 & 6.51 & 11.2 & 11.0 & 5.76 & 7.98 & 0.235 \\
\hline milky & 12.8 & 4.15 & 9.27 & 7.85 & 7.66 & 5.94 & 0.254 \\
\hline starchy water & 25.7 & 23.0 & 30.0 & 32.6 & 23.1 & 32.4 & 0.402 \\
\hline eggy & 7.68 & 1.46 & 1.98 & 2.49 & 1.89 & 6.45 & 0.173 \\
\hline \multicolumn{8}{|l|}{ mouthfeel } \\
\hline smooth & 50.7 & 48.9 & 52.7 & 46.0 & 38.6 & 44.5 & 0.316 \\
\hline effort to chew & 38.3 & 45.7 & 36.6 & 43.8 & 47.0 & 41.3 & 0.489 \\
\hline drying & 33.7 & 36.8 & 32.3 & 31.9 & 34.5 & 34.9 & 0.981 \\
\hline cohesive & $44.1^{\mathrm{ab}}$ & $22.4^{\mathrm{c}}$ & $44.6^{\mathrm{ab}}$ & $54.8^{\mathrm{a}}$ & $28.1^{\mathrm{bc}}$ & $39.6^{\mathrm{abc}}$ & $<0.0001$ \\
\hline watery & 12.2 & 4.55 & 10.5 & 12.3 & 8.09 & 11.0 & 0.376 \\
\hline \multicolumn{8}{|l|}{ after-effect } \\
\hline popcorn & 18.1 & 11.3 & 22.1 & 12.2 & 10.7 & 7.70 & 0.057 \\
\hline salty & 7.84 & 11.2 & 7.98 & 11.4 & 7.85 & 4.48 & 0.765 \\
\hline sweet & 22.6 & 18.8 & 21.6 & 20.1 & 17.8 & 20.5 & 0.912 \\
\hline bitter & 5.77 & 3.49 & 3.35 & 6.99 & 8.43 & 7.18 & 0.664 \\
\hline drying & 27.8 & 31.8 & 28.0 & 23.7 & 29.9 & 32.9 & 0.766 \\
\hline residue & 27.8 & 16.8 & 28.4 & 26.0 & 22.8 & 24.6 & 0.664 \\
\hline starchy water & 23.0 & 20.2 & 20.7 & 27.0 & 19.6 & 26.8 & 0.639 \\
\hline
\end{tabular}

